\title{
The Design and Simulation Analysis of Electromechanical Double Acting Pneumatic Brake Valve
}

\author{
Qinghe Liu ${ }^{a}$, Guanghui Guo ${ }^{b}$ and Fufan $\mathrm{Qu}^{\mathrm{c}}$ \\ School of Automobile Engineering, Harbin Institute of Technology at Weihai, Weihai 264209, China \\ a70872879@qq.com, bhuiguoguang1006@163.com, 'cqufufan@126.com
}

Keywords: Pneumatic brake valve, composite braking system, PID control, pressure value.

\begin{abstract}
With the increasingly severe environmental and energy issues, the application of urban electric buses is more popular, but the battery reserve capacity has restricted the popularity of electric vehicles. Regenerative braking energy recovery system can reduce the energy consumption of the electric vehicle, and increase the mileage of electric vehicle. To solve this problem, this paper designed a new type of mechanical and electrical double acting pneumatic brake valve, as the executive component of the pneumatic brake system, and completed its mathematical modeling and simulation analysis. The model of the pneumatic braking system was established and by using the PID controller, the pressure value of the pneumatic brake system was controlled effectively. The results showed that the model can describe the working process of the brake valve accurately, and had a fast time response and a high control precision.
\end{abstract}

\section{Introduction}

The storage capacity of the battery is one of the major limiting factors in the development of electric vehicles. The driving range of electric vehicle is limited in a single battery charge, so it is the main topic of the research of electric vehicle to reduce the consumption of battery power and recycle energy as much as possible. As a separate motor brake cannot guarantee the braking safety, electric buses adopt composite brake by pneumatic braking and motor braking. Brake valve is the most important part of the whole braking system, determining the value of the brake pressure value of the brake air chamber. Therefore, many scholars have done research on the pneumatic brake valve. The literature [1-2] use multi domain modeling software to model and analyze the key parts of pneumatic brake valve, obtaining the results of dynamic response so as to provide a theoretical basis for the optimization of the structure and the coordination of the system output. Beijing Institute of Technology Tan Tao uses the method of theoretical analysis and simulation experiment, based on closed loop feedback theory, shortening the braking distance of the passenger car and improving the braking stability [3]. Zhu Qiang established the simulation test bench of the vehicle air pressure brake to simulate the output pressure of the brake air chamber, accurately describing the change characteristics of the output pressure of the brake air chamber [4]. Under the control strategy of regenerative braking, the literature [5] analyzed the dynamic response of pneumatic brake, and the experimental results can meet the requirements of braking stability and energy recovery. The bond graph model of the dual chamber brake valve established in the literature [6], effectively describe the braking force of each component of the pneumatic braking system and flow and causality of control signals.

However, the research on the linear control of the bus braking is still in the exploratory stage. In this situation, a new type of pneumatic brake valve was designed, which can be carried out by mechanical and electromagnetic force, to provide the hardware foundation for the linear braking control of the electric bus.

\section{Design of Double Action Pneumatic Brake Valve}

In this paper, the design of the brake valve must meet the structural requirements of the serial composite braking system. A complete function of the serial composite braking system must have the 
following functions: 1)Ensure the braking safety; 2)Effective recovery of braking energy; 3)Drivers have a clear feeling; 4)Braking system structure with controllable braking force; 5)Reliable mechanical backup braking capability.

The designed schematic diagram of the electromechanical double acting pneumatic brake valve is shown in Fig.1. Its working principle is as follows:

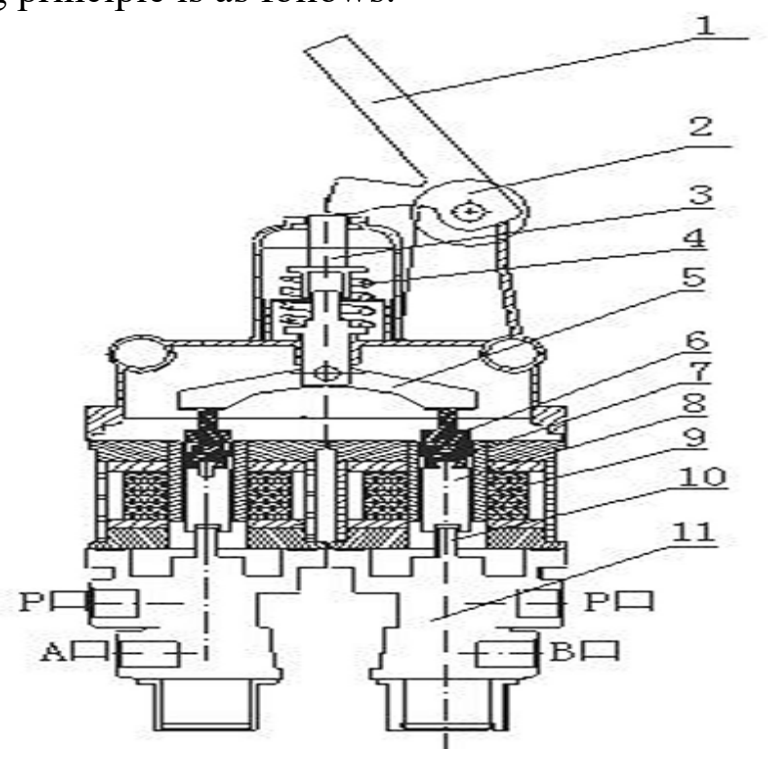

Fig. 1 Schematic diagram of the brake valve

Like the parallel dual chamber brake valve, the electric control operating mechanism part includes two parts of the left and right symmetry, and each part consists of a magnet drive rod 6, a spring 7, an armature 8 , and a magnet coil 9 . The force of brake pedal 1 will apply on the magnet transmission rod 6 through the drive rod 3 , spring 4 , force lever 5, and magnet drive spring 7 one by one, and at the end the pedal force will be transferred to the armature 8 . The armature also receives the electromagnetic force of electromagnetic coil 9, and both of the force makes the spool 10 open, then the pressure of ports A and B will be determined by the opening size of the valve body 11 . Then, by controlling the electromagnet force respectively, we can control the output pressure of each cavity, which makes the valve has ability of the linear control.

\section{Modeling and Simulation Analysis of Pneumatic Braking System}

The Model of Mechanical Part. According to the structure and working process of the double action pneumatic brake valve, the simplified model is shown in Fig. 2. The left is internal structure diagram, simplifying model by assuming the components of a common movement as a whole, then we got simplified model shown on the right.
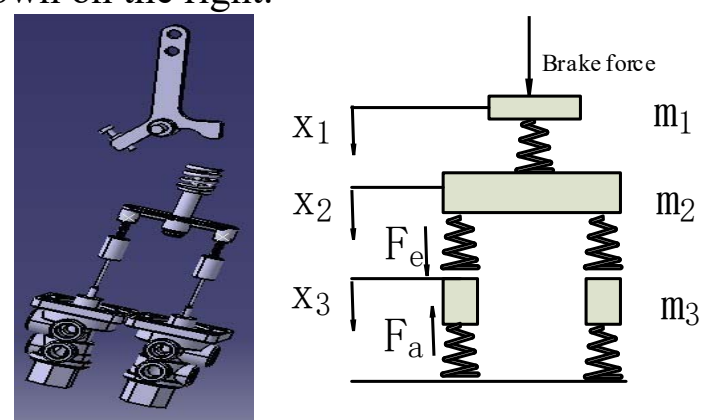

Fig. 2 Simplified model of pneumatic brake valve

Analyzing the forces between various components, the brake pedal is subjected to the driver's input pedal force and reaction force of the return spring under the brake pedal. According to this process, the formula 1 is got.

$$
m_{1} \ddot{x}_{1}=F-k_{1}\left(x_{1}-x_{2}\right)
$$


Where, $m_{1}$ represents brake pedal mass $(\mathrm{kg}) ; \quad F$ represents pedal force $(\mathrm{N}) ; \quad k_{1}$ represents stiffness of pedal return spring.

Under the action of force transmission spring, the force lever get down. While the two sides of the lever are respectively subjected to the reaction force of the force spring of the brake valve, making it back. According to this process, the formula 2 is got.

$$
m_{2} \ddot{x}_{2}=k_{1}\left(x_{1}-x_{2}\right)-k_{21}\left(x_{2}-x_{31}\right)-k_{22}\left(x_{2}-x_{32}\right)
$$

Where, $m_{2}$ represents force lever mass $(\mathrm{kg}) ; k_{21}$ represents stiffness of controlling front axle brake transmission spring; $k_{22}$ represents stiffness of controlling rear axle brake transmission spring.

Under the force of transmitting spring, the spool of the pneumatic valve is downward, then the brake air chamber begins to inflate, pressure lifting. Pressure acting on the valve core of the feedback area, result in upward force. Meanwhile the return spring of the pneumatic valve produce the upward restoring force due to the downward movement of the valve core. Because of both of them combined acting, spool get back. According to this process, the formula 3 and 4 is got.

$$
\begin{aligned}
& m_{3} \ddot{x}_{31}=k_{21}\left(x_{2}-x_{31}\right)-k_{31} x_{31}+F_{e}(t)-F_{a}(t) \\
& m_{3} \ddot{x}_{32}=k_{21}\left(x_{2}-x_{32}\right)-k_{32} x_{32}+F_{e}(t)-F_{a}(t)
\end{aligned}
$$

Where, $m_{3}$ represents mass of valve core $(\mathrm{kg}) ; k_{31}$ represents stiffness of front axle brake valve return spring; $k_{32}$ represents stiffness of rear axle brake valve return spring; $F_{e}(t)$ represents electromagnetic force $(\mathrm{N}) ; F_{\mathrm{a}}(t)$ represents pressure restoring force $(\mathrm{N})$ 。

According to the above formula and mechanical model, the movement process of the valve core is obtained, as is shown in Fig. 3. Spool under the action of force, quickly open, achieving maximum value. Brake chamber pressure begin to rise, the feedback force generated by the pressure increasing, while the reaction force of the valve core return spring increases. Both of them combined acting promote the spool back. With the increase of the feedback force, Spool begin to gradually return.

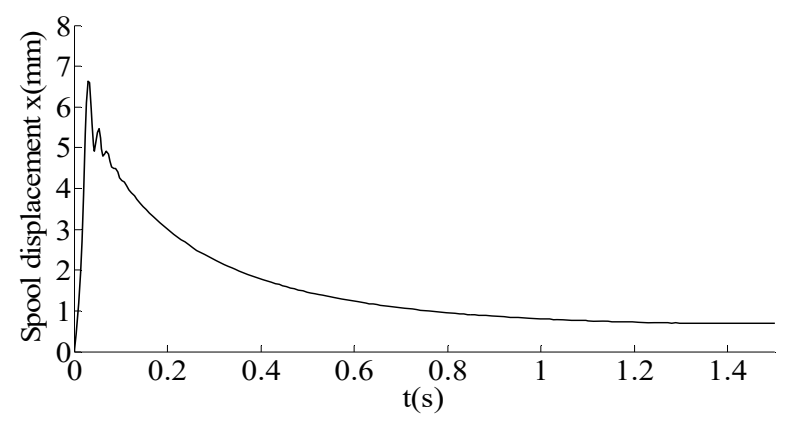

Fig. 3 Spool movement diagram

Model of Pneumatic Part. As the temperature change was very small, this paper assume that the process was isothermal. The volume flow of gas flowing through the air pressure valve is proportional to the opening of the valve. Then formula 5 is got. According to the relationship between volume flow and mass flow, formula 6 is got. Change of air pressure is shown in formula 7 .

$$
\begin{gathered}
q_{v}=C_{d} w x_{31} \sqrt{\frac{2 \Delta p}{\rho}} \\
q_{m}=\frac{q_{v} p_{1}}{R_{g} T} \\
\Delta p=\frac{\int q_{m} d t R_{g} T}{V}
\end{gathered}
$$

Where, $q_{v}$ represents volume air flow; $T$ represents mass air flow; $K$ represents source air pressure $(\mathrm{Pa}) ; T$ represents brake system temperature $(K)$. 
As for the electromagnet, taking into account the magnetic flux leakage, formula 8 is got. According to the structure of the braking air chamber, the equation of motion is established during its working progress, shown in formula 9.

$$
\begin{aligned}
F & =\frac{(N I)^{2} \mu_{0} S}{2 K_{f}^{2} \delta^{2}} \\
m \ddot{x} & =\left(P_{c}-P_{a}\right) S_{c}-K_{1} X-F^{\prime}
\end{aligned}
$$

Where, $m$ represents push rod mass; $K_{1}$ represents spring stiffness; $F$ ' represents push rod reaction force $(\mathrm{N}) ; P_{c}$ represents brake chamber inlet pressure $(\mathrm{Pa}) ; p_{a}$ represents brake chamber outlet pressure $(\mathrm{Pa})$.

Based on the modeling analysis above, the braking force is shown in Fig. 4. The air pressure of the brake system of the pure electric bus is $0.5 \mathrm{MPa}$, greater than $10 \%$ of the factory fixed pressure. And after $0.6 \mathrm{~s}$, air pressure reach $0.45 \mathrm{MPa}$, greater than $75 \%$ of the factory fixed pressure. The results of simulation meet the requirements.

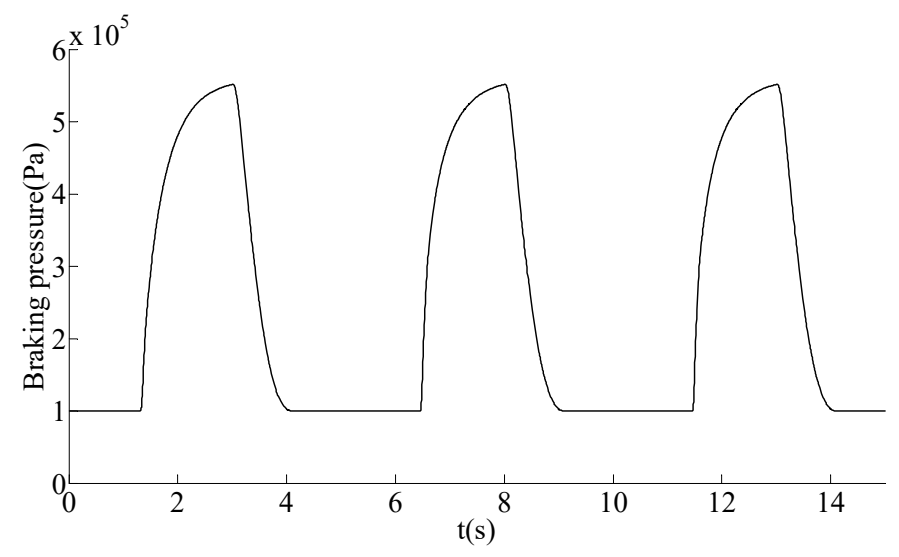

Fig. 4 dynamic curve of continuous braking

\section{Simulation Aanalysis of Pneumatic Braking System Based on PID Control}

PID controller is one of the most common control methods, and its control law is expressed by (10):

$$
u(t)=K_{p}\left[e(t)+\frac{1}{T_{1}} \int_{0}^{t} e(t)+T_{D} \frac{d e(t)}{d(t)}\right]
$$

Where, $K_{\mathrm{p}}$ represents regulator gain; $T_{\mathrm{I}}$ represents integral time; $T_{\mathrm{D}}$ represent differential time; $u(t)$ represents the output value of regulator; $e(t)$ represents the difference between the preset value and the feedback value.

The PID controller was added in the air pressure brake system model, as shown in the left of Fig. 5. Taking into account the work force to the brake valve from pedal is very small, only the electromagnetic force was considered. In the model, the PID parameters were determined firstly. Make target braking force as the input, and the force of the brake chamber was shown in the right of Fig. 5. 

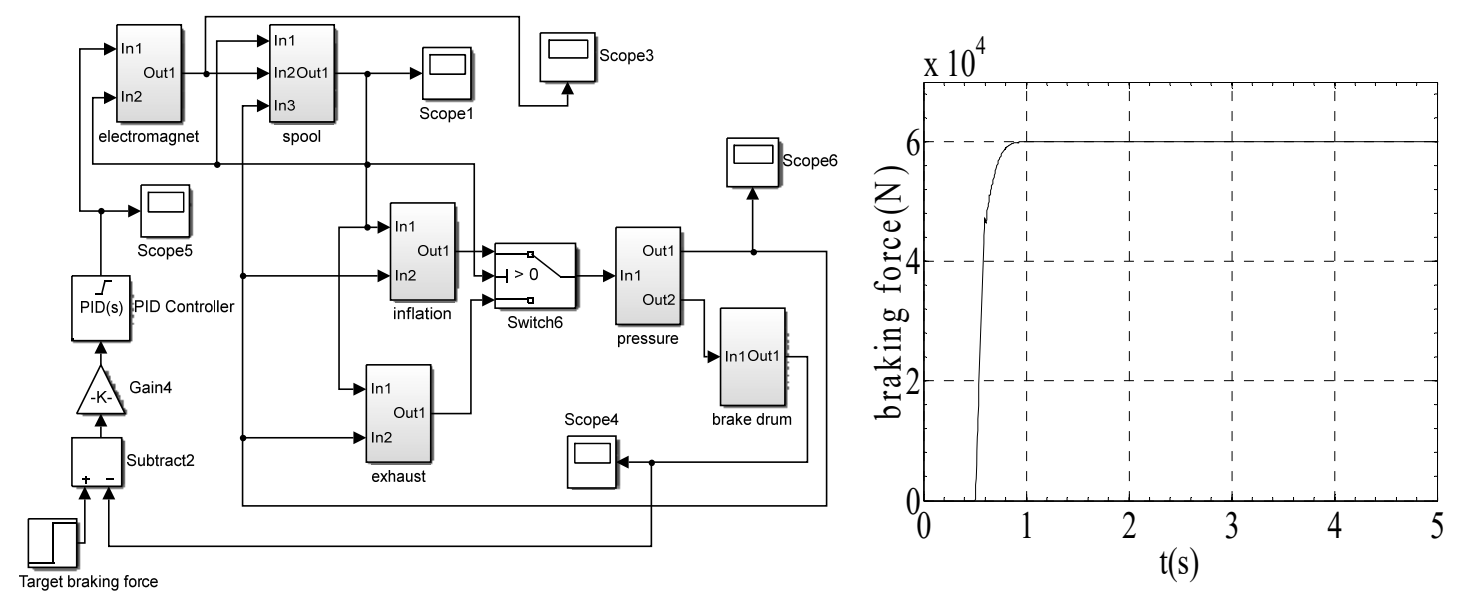

Fig. 5 Pneumatic brake model and the result

When an input was given in $0.5 \mathrm{~s}$ time, the brake air chamber begins to inflate, and braking force began to rise. Target braking force achieved stable value in $0.9 \mathrm{~s}$ time, and the dynamic response is rapid, and the accuracy is high.

\section{Summary}

In this paper, a new type of electromechanical double acting pneumatic brake valve was designed for the serial compound braking system, and the model of the pneumatic braking system was set up. The result showed that the output of the model can meet the target force, and have a quick response under the action of the PID controller, which can meet the requirement of braking force.

The designed brake valve can meet the purpose of serial composite brake by wire in theory. More importantly, it provided a hardware and theoretical basis for the more recovery of energy during braking.

\section{Acknowledgements}

The authors would like to thank the financial support of Shandong science and technology research program project (2014GGX105006).

\section{References}

[1] Yan Shi, Modeling and Experimental Verification of Key Brake Components of Pneumatic Brake System in Passenger Car [D]. China Jiliang University, 2014.

[2] Chen Qian, The Simulation Research of Pneumatic Braking System's Dynamic Characteristic for Commerical Vehicle[D]. Jilin University, 2015.

[3] QIN Tao, LI Gang-yan, TU Ming, Bus Pneumatic Braking Circuit Analysis and Control[J]. Transactions of Beijing Institute of Technology, 2012, 32(5):470-474.

[4] Zhu Q, Yi L U, Guo B, et al. Model of Output Pressure for Air-brake System in Passenger Car[J]. Chinese Hydraulics \& Pneumatics, 2015.

[5] Huang Xiaobo, Study on performation analysis and control strategies of regerative brake syatem for HEV bus[D].Hunan university, 2012.

[6] Chen Y. Dynamic simulation model of automobile compressed air brake system based on bond graph theory[J]. Journal of Traffic \& Transportation Engineering, 2005. 